\title{
Estados Unidos, Segunda Escravidão e a Economia Cafeeira do Império do Brasil
}

United States, Second Slavery, and the Brazilian Coffee Economy

Rafael de Bivar Marquese

Professor no Departamento de História da Universidade de São Paulo (FFLCH/USP - São Paulo/ Brasil)

e-mail: marquese@usp.br

\section{Resumo}

0 artigo comenta o ensaio de Edward E. Baptist, A Segunda Escravidão e a Primeira República Norte-Americana, com base na constatação de que o Sul dos Estados Unidos representou o coração da estrutura histórica da Segunda Escravidão. Neste sentido, a história da Primeira República NorteAmericana pode ser considerada como componente essencial da história do Império do Brasil. 0 artigo explora essa ideia por meio de um rápido exame da economia cafeeira brasileira.

\section{Abstract}

The present article comments on Edward E. Baptist's essay The Second Slavery and the First American Republic considering his statement that the US South represented the core of the Second Slavery. Therefore, the history of the First American Republic can be considered an essential component of the history of the Brazilian Empire. The article explores such an idea by means of a brief exam of the Brazilian coffee economy.

Palavras-chave

escravidão, café, Estados Unidos, Brasil

Keywords

slavery, coffee, United States, Brazil 
Ver os três ensaios de abertura de TOMICH, Dale. Pelo Prisma da Escravidão. Trabalho, Capital e

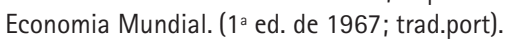
São Paulo: Edusp, 2011.

2

Um autor representativo dessa perspectiva, e que vem sendo bastante lido no Brasil, é BAILYN, Bernard. As origens ideológicas da Revolução Americana (trad.port.). Bauru: Edusc, 2003.

3

LYND, Staughton. Class Conflict, Slavery, and the United States Constitution (1 a ed. de 1967). Cambridge: Cambridge University Press, 2009; MORGAN, Edmund. American Slavery, American Freedom. The Ordeal of Colonial Virginia. New York: W.W.Norton, 1975; OAKES, James. Slavery and Freedom. An Interpretation of the Old South. New York: Vintage, 1990.

4

Ver, dentre outros trabalhos, MARQUESE,

Rafael de Bivar. Feitores do Corpo, Missionários da Mente. Senhores, letrados e o controle dos escravos nas Américas, 1660-1860. São Paulo: Companhia das Letras, 2004. p.259-376; SALLES, Ricardo. Eo Vale era o escravo. Vassouras, século XIX. Senhores e escravos no coração do Império. Rio de Janeiro: Civilização Brasileira, 2008; EL YOUSSEF, Alain. Imprensa e escravidão. Política e tráfico negreiro no Império do Brasil (Rio de Janeiro, 1822-1850). (Dissertação de Mestrado em História Social). Faculdade de Filosofia, Letras e Ciências Humanas, Universidade de São Paulo, São Paulo, 2010; BERBEL, Márcia; MARQUESE, Rafael; PARRON, Tâmis. Escravidão e Política. Brasil e Cuba, c.1790-1850. São Paulo: Hucitec 2010; PARRON, Tâmis. A política da escravidão no Império do Brasil, 1826-1865. Rio de Janeiro: Civilização Brasileira, 2011; SALLES, Ricardo. 0 Império do Brasil no contexto do século XIX. Escravidão nacional, classe senhorial e intelectuais na formação do Estado. Almanack. Guarulhos, n.04, p.5-45, 2 semestre de 2012.

5

MARQUESE, Rafael de Bivar; PARRON, Tâmis Peixoto. Internacional escravista: a política da Segunda Escravidão. Topoi, v.12, n.23, p.97-117, dez. 2011.
Ao propor o conceito da Segunda Escravidão em ensaio originalmente publicado vinte e cinco anos atrás, o historiador norte-americano Dale Tomich procurou quebrar com variantes consagradas das histórias nacionais da Inglaterra, da França, dos Estados Unidos, do Brasil e de Cuba, que sempre tomaram o século XIX como o "século da emancipação". Na medida em que o conceito tem ganhado cada vez mais espaço entre historiadores que trabalham com a escravidão negra oitocentista, aqui e alhures, vale lembrar quais foram os interlocutores imediatos de Tomich ao elaborá-lo. Seu ensaio fundou-se em um diálogo crítico com as principais vertentes de estudo da transição do feudalismo para o capitalismo, tal como expressa nas formulações de Immanuel Wallerstein e Robert Brenner, e com os esforços de caracterização abrangente da economia escravista do século XIX contidos nos trabalhos de Eugene Genovese e da New Economic History. É importante ressaltar que, não obstante toda sua crítica a Wallerstein, Tomich concebeu o conceito da Segunda Escravidão a partir do campo teórico e metodológico aberto pela perspectiva do sistema-mundo, trazendo para o primeiro plano analítico as forças estruturais do capitalismo global que moldaram a escravidão negra oitocentista nas Américas. Com efeito, ao se valer de uma noção de capitalismo histórico que não vê as relações entre trabalho escravo e trabalho assalariado como externas umas às outras, porém estrutural e dialeticamente integradas, Tomich apresentou um modelo altamente sugestivo para examinar as interconexões estreitas entre o mundo criado pela Revolução Industrial e o mundo produzido pela expansão da escravidão nas novas fronteiras da mercadoria do espaço americano. ${ }^{1}$

No texto ora submetido a debate, Edward Baptist emprega a categoria Segunda Escravidão para reenquadrar a história dos Estados Unidos no século XIX. Como ele bem ressalta, a visão liberal consagrada pela historiografia nacionalista norte-americana viu na escravidão negra um acidente de percurso no progresso do país, e na Guerra Civil a correção do rumo traçado em $1776 .{ }^{2}$ Dando prosseguimento a uma vertente que se iniciou ainda no final da década de 1960 com Staunghton Lynd, e que teve continuidade, dentre outros, com Edmund Morgan nos anos setenta e James Oakes na década de 1990, Baptist revê o lugar da escravidão negra na história norte-americana. ${ }^{3}$ Mas, o faz de modo muito inovador, ao tomar por eixo de sua análise o mundo das finanças. Seu texto não apenas propõe uma nova periodização da trajetória dos Estados Unidos, que tem na Segunda Escravidão em sua face sulista o elemento estruturador do que define como a "Primeira República norte-americana", como igualmente aponta para a centralidade do capital financeiro nesta história.

Não me cabe sumariar o argumento de Edward Baptist, haja vista que o leitor o tem diante de si. Meu rápido comentário se articula aos seus dois pontos de partida: tal como ele, também irei me reportar ao problema do dinamismo econômico e da estrutura política, tendo por foco, no entanto, o Império do Brasil. Este não é um procedimento artificial ou arbitrário. Ao lado de outros colegas brasileiros, há mais de dez anos tenho utilizado o conceito da Segunda Escravidão para compreender o sistema escravista e a formação do Estado nacional brasileiro nos quadros da economia-mundo capitalista do século XIX. ${ }^{4}$ Em um desses trabalhos, demonstramos de que forma o Sul dos Estados Unidos funcionou como o eixo da estrutura histórica da Segunda Escravidão e, portanto, como a Primeira República norte-americana deve ser tomada como uma componente de peso na conformação dos destinos do Império do Brasil. ${ }^{5}$ Tendo por objeto a cadeia 
mercantil do café, o objetivo das notas que se seguem é tão somente indicar como a escrita da história do Brasil oitocentista pode avançar se formos capazes de atrelá-la à história dos Estados Unidos.

FURTAD0, Celso. Formação econômica do Brasil. (1a ed. de 1959). São Paulo: Companhia das Letras, 2009
GRAHAM, Richard. Economics or Culture? The Development of US South and Brazil in the Days of Slavery. In: GISPEN, Kees (ed.) What Made the South Different? Jackson: University Press of Mississippi, 1990. p.109. Versão reduzida desse artigo foi publicada anteriormente em português - GRAHAM, Richard. Escravidão e desenvolvimento econômico: Brasil e Estados Unidos no século XIX. Estudos Econômicos, v.13, n.1, p.223-257, 1983.

8

Ver nota 5.
0 procedimento de comparar essas duas histórias não constitui novidade. Sem voltarmos para o próprio século XIX, basta lembrarmos a importância que um exercício dessa natureza teve para o tratamento da problemática do desenvolvimento e do subdesenvolvimento na obra de Celso Furtado. ${ }^{6}$ No entanto, para expor a ideia básica de meu comentário ao ensaio de Edward Baptist, gostaria de me valer de um trabalho cujo foco recai exatamente sobre o cotejamento da escravidão negra no Brasil e nos Estados Unidos oitocentistas.

Trata-se de um artigo pioneiro e muito estimulante de Richard Graham, no qual ele procede a uma comparação sistemática entre a economia da escravidão no Brasil e nos Estados Unidos ao longo do século XIX. 0 objetivo de Graham é compreender a razão da diferença notável do desempenho da economia escravista sulista em relação à brasileira, haja vista que a primeira era bem mais desenvolvida no que se refere à rede de transportes, técnicas agronômicas e manufaturas. Graham explica essa assimetria levando em conta um conjunto relativamente amplo de fatores econômicos, sociais, políticos e culturais, destacando em particular os lugares diferentes que o algodão e o café ocuparam no mercado mundial como o fundamento das trajetórias distintas de desenvolvimento econômico. 0 algodão foi matéria-prima essencial da economia industrial do século XIX, ao passo que, mesmo com seu consumo massificado e seu papel de estimulante para os trabalhadores urbanos, o café não passou de uma bebida inter-refeições e de sobremesa. Os impactos dessa diferença para o desempenho das duas regiões rapidamente se fizeram sentir. Nas palavras de Graham,

\section{Com exceção dos últimos 25 anos de vigência da escravidão, o valor anual das exportações de algodão do Sul suplantou o valor das exportações de café do Brasil em uma proporção de dois para um, não raro com uma razão ainda maior. Ademais, essa diferença foi cumulativa. (...) 0 algodão ofereceu para o conjunto dos Estados Unidos uma capacidade de compra de bens de capital bem maior do que o café proveu para o Brasil, e os fazendeiros de algodão tinham muito mais riqueza para investir em ferrovias, indústrias e implementos e maquinário agrícola do que os fazendeiros de café.}

Não obstante sua correção, nota-se nessa passagem - como de resto em todo o artigo - o problema metodológico comum das comparações correntes entre a escravidão brasileira e a norte-americana, isto é, o exame dos dois paises como unidades separadas e independentes uma da outra. Noutras palavras, a profunda integração histórica entre a escravidão negra nos dois paises passou despercebida a Richard Graham, que não apreendeu dois pontos cruciais dessas relações: 1) a subordinação do café brasileiro aos ritmos da economia norte-americana, tanto no que se refere à sua destinação final como à formação de preços; 2) a estrita articulação dos destinos políticos da escravidão no Império do Brasil aos destinos políti$\cos$ da escravidão na federação norte-americana. Como o segundo ponto foi abordado em trabalho anterior, ${ }^{8}$ irei me concentrar nas relações da economia cafeeira do Brasil com o mercado consumidor norte-americano. Vejamos, de início, o seguinte quadro: 


\begin{tabular}{lcc}
\hline & Sacas & Percentagem das exportações brasileiras \\
\hline $\begin{array}{l}\text { Europa } \\
\text { (população estimada em } \\
\text { 1850: c.276 milhões) }\end{array}$ & 642.827 & 53,21 \\
$\begin{array}{l}\text { Estados Unidos } \\
\text { (população estimada em }\end{array}$ & 551.276 & 45,63 \\
$\begin{array}{l}\text { 1850: c.23 milhões) } \\
\text { Total }\end{array}$ & 1.208 .062 & 100 \\
\hline
\end{tabular}

Os dados sobre a produção mundial em 1845 foram retirados de SAMPER, Mario; FERNANDO, Radin. Historical Statistics of Coffee Production and Trade from 1700 to 1960. In: CLARENCESMITH, William Gervase; TOPIK, Steven.(eds). The Global Coffee Economy in Africa, Asia, and Latin América, 1500-1989. Cambridge: Cambridge University Press, 2003. p.418 e p.432. A informação sobre as exportações brasileiras na década de 1890 foi obtida no "Apêndice Estatístico" preparado por Mauro Rodrigues da Cunha para o livro 150 anos de Café. São Paulo: Marcellino Martins \& E.Johnston Exportadores Ltda., 1992. p.371.

10

McDONALD, Michelle Craig. From Cultivation to Cup: Caribbean Coffee and the North American Economy, 1765-1805. PhD Dissertation. Michigan: The University of Michigan, 2005. p.15.

11

TOPIK, Steven. The Integration of the World Coffee Market. In: CLARENCE-SMITH, William Gervase; TOPIK, Steven.(eds). The Global Coffee Economy... Op. Cit., p.37. Ver, também, McDONALD, Michelle Craig; TOPIK, Steven. Americaning Coffee: Remaking a Consumer Culture. In: TRENTMANN, Frank; NÜTZENADEL, Alexander (ed.). Food and Globalization. Consumption, Markets and Politics in the Modern World. Oxford: Berg Publishers, 2008.
Fonte: Anuário político, histórico e estatístico do Brasil - 1846 a 1847. Rio de Janeiro: Firmin Didot Irmãos, 1847. p.403.

Como se lê no quadro, quase metade das exportações brasileiras de café (cujo total equivalia, naquele momento, a cerca de metade da produção mundial) era encaminhada para os Estados Unidos, com um consumo per capita dez vezes maior do que o europeu. Essa relação se aprofundou ao longo da segunda metade do século XIX, para chegar, em seus anos finais, a uma ordem de 75\% das exportações brasileiras de café destinadas aos Estados Unidos. ${ }^{9}$

Em 1845, contudo, a relação era relativamente recente, ainda que a articulação dos Estados Unidos aos fluxos cafeeiros mundiais fosse antiga. 0 envolvimento dos norte-americanos nos circuitos caribenhos - então a maior região produtora mundial do artigo - datava da década de 1770 , acentuando-se após a Revolução de Independência, quando seus comerciantes desenvolveram uma complexa rede de reexportação de café, responsável, em 1804, por cerca de 10\% dos ganhos dos Estados Unidos com bens exportáveis. ${ }^{10}$ Com a normalização dos mercados atlânticos após as guerras napoleônicas e o fim de seu papel como intermediário neutro, os Estados Unidos passaram da condição de reexportadores para a de importadores de café. A demanda interna do produto, cujo consumo associou-se de modo indelével à própria identidade nacional, cresceu exponencialmente a partir da década de 1820, para o que a política tarifária foi decisiva. Como ressalta Steven Topik, "os Estados Unidos foram o único grande mercado a importar café livre de taxas, na medida em que as tarifas baixaram de 10 cents por libra em 1812 para 5 em 1814, tornando-se completamente livre após 1832"11.

0 peso do algodão e dos interesses escravistas no quadro político e econômico dos Estados Unidos desempenhou papel crucial no processo de atrelamento do café brasileiro ao mercado consumidor norte-americano, processo esse cujo ponto nevrálgico residiu exatamente na tarifação de 1832. Durante toda a década de 1820, os produtores escravistas de algodão estiveram dentre os mais ardorosos defensores do princípio do livre comércio internacional e da teoria das vantagens comparativas nos Estados Unidos, opondo-se vivamente a medidas protecionistas que privilegiassem os interesses manufatureiros do Norte e os dos agricultores de mantimentos do Meio-Oeste. Neste sentido, não espanta a profunda resistência que os exportadores escravistas demonstraram ao arranjo tarifário aprovado pelo Congresso Federal em 1828, que previa sobretaxas a uma série de produtos industriais e agrícolas importados pelos Estados Unidos: de acordo com a voz deles, jamais as manufaturas do Norte seriam capazes de absorver a 
Todo o parágrafo está baseado no capítulo 3 de SCHOEN, Brian. The Fragile Fabric of the Union. Cotton, Federal Politics, and the Global Origins of the Civil War. Baltimore: The Johns Hopkins University Press, 2009.

13

Arquivo Histórico do Itamaraty. Ofícios enviados de Washington ao Rio de Janeiro, 233/3/1.

Agradeço a Tâmis Parron, que me disponibilizou a reprodução desses documentos. crescente produção algodoeira do Sul, e tal protecionismo teria por consequência adicional a exclusão paulatina da matéria-prima sulista dos mercados britânicos. 0 apego aos princípios da economia política clássica forneceu aos produtores escravistas de algodão 0 arsenal ideológico para questionar as tarifas de 1828 , processo que logo desembocou no movimento político da Nulificação, liderado por John C. Calhoun, da Carolina do Sul. 0 acordo costurado por Andrew Jackson em 1832 não logrou apaziguar a oposição dos nulificadores ao poder do Congresso em estabelecer a política tarifária nacional, e somente uma nova tabela, aprovada em 1833, solucionou essa grave crise seccional. Importa destacar o fato de que, nas negociações entre representantes do Norte, do Sul e do Oeste, o café - ao lado do chá e do cacau - entrou na cota dos produtos que seriam isentos de tributação. ${ }^{12}$

0 representante diplomático do Império do Brasil nos Estados Unidos, acompanhando em Washington toda a pendenga em torno das tarifas e da pregação dos nulificadores calhounitas, não deixou de registrar as perspectivas econômicas abertas para o café brasileiro, que já vinha ganhando espaço no mercado consumidor norte-americano a expensas de seus rivais caribenhos. Em ofício de 11 de janeiro de 1831, José de Araújo Ribeiro anotou que "a importação de nosso café nesses Estados já rivaliza na sua quantidade com os de Cuba e São Domingos, e não há muito tempo uma pessoa que acabara de viajar pelo interior da referida ilha de Cuba aqui me disse que muitos lavradores abandonaram naquela ilha a cultura do café, queixando-se de não poder competir com os cafés do Brasil". Quando, em 28 de julho do ano seguinte, finalmente pôde noticiar ao Rio de Janeiro a aprovação de uma nova tabela tarifária pelo Congresso Federal, já nas primeiras linhas de seu ofício Araújo Ribeiro anunciou a boa nova: ao contrário da tarifa de 1828, a de 14 de julho de 1832 "isenta o café de todo direito"13.

0 impacto da medida para o atrelamento da produção brasileira ao mercado consumidor norte-americano foi decisivo. Os preços do café brasileiro desembarcado em Nova lorque sofreram notável queda entre 1821 e 1832, da ordem de 21 para 10 centavos de dólar por libra. No entanto, o decreto aprovado pelo Congresso em 1828 deu prosseguimento à taxa estabelecida em 1814 , o que significava que o preço do produto seria acrescido de 5 centavos de dólar antes de ser colocado à venda. Como se percebe, a tarifa livre de 1832 permitia a redução pela metade do preço do café a ser pago, a partir daquele ano, pelo consumidor final norte-americano. Suas implicações para a economia escravista brasileira foram imediatas:

Importação de café brasileiro pelos Estados Unidos:

\begin{tabular}{ccc}
\hline Período & Libras (média anual) & Percentagem da produção brasileira total \\
\hline $1825-1829$ & 36.788 .028 & $23 \%(1830)$ \\
$1830-1834$ & 111.074 .342 & $28 \%(1835)$ \\
$1835-1839$ & 192.627 .601 & $27,5 \%(1840)$ \\
$1840-1844$ & 319.044 .568 & $39 \%(1844)$ \\
\hline
\end{tabular}

Fonte: TAUNAY, Afonso d'Escragnolle. História do Café no Brasil. Rio de Janeiro: DNC, 1939, Vol.4. p.121-122. 
14

Os niveis de sobre-exploração do trabalho escravo na atividade algodoeira registrados por Edward Baptist são comparáveis ao que identifiquei para o café no Vale do Paraiba. Ver a respeito, MARQUESE, Rafael de Bivar. Diáspora africana, escravidão e a paisagem da cafeicultura no Vale do Paraíba oitocentista. Almanack Braziliense, São Paulo, n.7, p.138-152, maio de 2008. PARRON, Tâmis. A política da escravidão no Império do Brasil... Op. Cit., p130, lembra que a primeira petição pela reabertura do tráfico transatlântico de escravos foi endereçada pela Câmara Municipal de Bananal (SP) à Assembleia Geral justamente em 1834.

15

0 melhor trabalho sobre a trajetória da Maxwell, Wright \& Co., e que serviu de base para as informações contidas neste e nos próximos parágrafos, é o livro de JARNAGIN, Laura. A Confluence of Transatlantic Networks. Elites, Capitalism, and Confederate Migration to Brazil. Tuscaloosa: The University of Alabama Press, 2008. p.111-147. Sobre as companhias inglesas de importação / exportação no Rio de Janeiro, ver GORENSTEIN, Riva. Comércio e política: o enraizamento de interesses mercantis portugueses no Rio de Janeiro (1808-1830). In: MARTINHO, Lenira Menezes; GORENSTEIN, Riva. Negociantes e caixeiros na sociedade da Independência. Rio de Janeiro: Prefeitura da Cidade do Rio de Janeiro, 1992. p.142.

16

R00D, Daniel. An International Harvest: Slavery, the Virginia-Brazil Connection, and the Making of the McCormick Reaper. In: ROCKMAN, Seth; BECKERT, Sven (eds.). Slavery's Capitalism: A New History of American Economic Development. Philadelphia: University of Pennsylvania Press, no prelo. Agradeço a gentileza de Dan Rood em me disponibilizar esse excelente artigo.
Identifica-se, assim, a relação direta entre o terceiro momento financeiro identificado por Edward Baptist, o boom algodoeiro correspondente e o impulso para a notável expansão da cafeicultura brasileira a partir dos anos trinta. Na face brasileira, esse empuxo envolveu não apenas a criação de modalidades de administração dos recursos naturais e dos escravos profundamente espoliativas, mas, sobretudo, a pressão de seus fazendeiros pela reabertura do tráfico transatlântico de escravos, desde 1831 proibido nas letras da lei. ${ }^{14}$ Noutros termos, os quase 550.000 africanos que foram desembarcados como escravos nas províncias do Centro-Sul do Brasil entre 1835 e 1850 representaram a face local dos processos de escravização em massa promovidos pela expansão da Segunda Escravidão.

A articulação estreita entre a economia escravista norte-americana e a economia escravista brasileira até agora descrita pode ser observada, em outra escala, pela trajetória da firma Maxwell, Wright \& Co, surgida da conjunção de dois grupos familiares cujas trajetórias foram formativas da passagem da escravidão colonial para a Segunda Escravidão. Joseph Maxwell, um de seus fundadores, provinha de uma família com longa prática comercial no eixo Portugal-Inglaterra. Ele aportou no Rio de Janeiro com apenas 16 anos, no ano imediato à transferência da família real portuguesa. Em 1811, casou-se com Maria Rosa de Sousa, pertencente ao ramo familiar dos Sousa Coutinho, o que Ihe abriu as portas da poderosa comunidade mercantil luso-brasileira sediada na então cabeça do Império português. Com o também inglês John Rudge, com idade igual à sua e tendo chegado ao Brasil na mesma época, Joseph Maxwell fundou a firma Maxwell, Silva \& Co, uma das muitas companhias estrangeiras surgidas no Rio de Janeiro após a abertura dos portos que paulatinamente adquiriram controle do setor de importação e exportação em grande volume. ${ }^{15}$

A familia Wright, por sua vez, tinha suas origens na baia de Chesapeake. Robert Wright, além de grande mercador e senhor de escravos, foi deputado federal, senador e governador do Estado de Maryland. Seu filho William H. DeCourcy Wright ocupou, entre 1825-1831, o cargo de cônsul dos Estados Unidos no Brasil, quadra em que o Brasil firmou com a República norte-americana o Tratado de Paz, Amizade, Comércio e Navegação (1828) regulando as trocas comerciais entre os dois países. Não se sabe ao certo a data em que em William Wright associou-se a Joseph Maxwell e John Rudge para fundar a Maxwell, Wright \& Co, mas, a partir de 1827, a firma passou a aparecer com frequência nos registros da imprensa do Rio de Janeiro concernentes ao comércio externo. A movimentação portuária aí anotada permite ver como ela se envolveu, primeiramente, com a importação de farinha de trigo norte-americana para o mercado brasileiro. Como destaca o historiador Daniel Rood, "nos trinta anos anteriores à Guerra Civil, o Brasil se tornou o principal mercado exportador para a farinha de trigo norte-americana"16. Richmond e Baltimore foram os dois grandes portos de saída do produto. A farinha de Chesapeake, que por suas caracteristicas capazes de resistir bem à travessia oceânica para os trópicos, ganhava da farinha do Meio-Oeste dos Estados Unidos e da Europa, já no começo da década de 1820 havia quebrado a produção cerealífera do Rio Grande do Sul. Devemos lembrar ainda que, se Chesapeake era a principal zona exportadora de farinha de trigo para o Brasil, também o era de escravos para a fronteira algodoeira do Deep South norte-americano.

No começo dos anos 1830, quando a República aboliu as tarifas de importação de café e a chamada "guerra de las harinas" entre a Espanha e 
Anuário político, histórico e estatístico do Brasil 1846 a 1847. Rio de Janeiro: Firmin Didot Irmãos, 1847, p.404; Jornal do Comércio, Ano XXI, n.26, 26 de janeiro de 1846, p.1.

18

Agradeço a Leonardo Marques pelas nossas conversas sobre 0 assunto. Sobre os demais trabalhos, ver CONRAD, Robert. Tumbeiros. 0 tráfico de escravos para o Brasil. (trad.port.) São Paulo: Brasiliense, 1985. p.165; JARNAGIN Laura. Op. Cit., p.128; HORNE, Gerald. The Deepest South:The United States, Brazil, and the African Slave Trade. New York: New York University Press, 2007. p.9; GUIMARÃES, Carlos Gabriel. La independencia e las finanzas de Brasil: comentarios sobre la dependencia de Brasil a partir del comportamiento de las empresas británicas, 1820-1850: 0 caso da Samuel Phillips \& Co. Paper apresentado ao $X$ Congreso Internacional de la $A E H E$, Universidad Pablo de Olavide, Sevilla, Septiembre de 2011.

19

NABUCO, Joaquim. Um Estadista do Império. 3v. Rio de Janeiro: Garnier, 1897, vol.I, p.256-258. Todas as passagens doravante citadas foram retiradas daqui. os Estados Unidos excluiu o produto norte-americano de Cuba, a Maxwell, Wright \& Co, ao lado de outras firmas norte-americanas estabelecidas no Rio de Janeiro, logrou articular diretamente a importação da farinha de trigo à exportação de café. Essas companhias criaram um circuito comercial perfeito, no qual as barcas que traziam farinha da Virginia e de Maryland retornavam, para os Estados Unidos, com café brasileiro. Os montantes relativos dessas operações ainda exigem mais pesquisa para serem quantificados com alguma precisão; o sucesso da Maxwell, Wright \& Co, no entanto, não pode ser colocado em dúvida. Em meados dos anos quarenta, ela despontava como a maior companhia exportadora de café brasileiro. Das 551.276 sacas enviadas do Brasil para os Estados Unidos em 1845, 178.034 - ou 32,30\% de todas as exportações de café do Império para a República - foram por ela remetidas. ${ }^{17}$

$\mathrm{Na}$ trajetória da Maxwell Wright \& Co, podemos ver a passagem do sistema comercial criado logo após a fuga da família real portuguesa para o Rio de Janeiro, com o domínio dos mercadores britânicos sobre o ramo de importação e exportação em larga escala, para o sistema comercial fundado na exportação cafeeira, com grande presença de mercadores norte-americanos. Mas, não apenas isso: podemos ver, igualmente, a passagem das engrenagens do tráfico transatlântico legal de escravos para as do tráfico ilegal. As relações dessa companhia com o tráfico negreiro após 1835 são nebulosas, e exigem maiores pesquisas - é o que o historiador Leonardo Marques realiza neste momento, em sua tese de doutorado em finalização na Emory University. De todo modo, de acordo as informações que ele fornece, precedidas por levantamentos prévios de outros historiadores, sabe-se que a firma vendeu, no Rio de Janeiro, um grande número de vasos fabricados em Baltimore que foram diretamente empregados no tráfico transatlântico de escravos para o Brasil, além de, em 1840, ter atestado publicamente no Jornal do Comércio - ao lado de outras grandes firmas exportadoras sediadas na Corte - a idoneidade do grande traficante Manoel Pinto da Fonseca. ${ }^{18}$

Há, ainda, uma evidência indireta do envolvimento da Maxwell Wright \& Co no tráfico ilegal, que pode ser obtida no depoimento que Robert Clinton Wright (sócio majoritário da firma após 1849) prestou à Comissão de Inquérito nomeada em 1859 para examinar as causas do impacto da crise financeira mundial de 1857 sobre o sistema bancário brasileiro e o meio circulante local, transcrito por Joaquim Nabuco na biografia de seu pai. ${ }^{19}$ Segundo Robert C. Wright, o fim do tráfico permitiu ao Brasil manter recursos que eram majoritariamente empregados para a compra de escravos na África; até aquele momento, "os costumes dos Brasileiros, pela maior parte, eram simples no extremo, de uma frugalidade exemplar". 0 excesso de metal que retornou ao Brasil após 1850 levou à expansão do meio circulante, estimulado também pela criação indiscriminada de bancos de emissão. Houve, então, um impulso direto à "corrupção de hábitos" de 1854 em diante, pelas facilidades dadas à livre emissão bancária e ao consumo desenfreado. Daí a defesa aberta, por Wright, da ordem pregressa, vigente durante a era do tráfico negreiro ilegal por todos praticado:

Antes bons negros da costa d'África para felicidade sua e nossa, a despeito de toda a mórbida filantropia Britânica, que esquecida da sua própria casa deixa morrer de fome o pobre irmão branco, escravo sem senhor que dele se compadeça, e hipócrita ou estólida chora, exporta ao ridículo da verdadeira filantropia, o fado do nosso 
HOLANDA, Sérgio Buarque de. Raízes do Brasil. (1 ${ }^{\text {a }}$ ed: 1936). Rio de Janeiro: José Olympio, 1989, p. 45

21

Em suas palavras, "Maxwell, Wright had to contend with 'commercial dificulties' in the US engendered by the Panic off 1837, which seemed to get 'worse and worse', 'if possible, failure of large houses' would be 'occcuring daily in N.York \& New Orleans, some in Boston'. The message to Rio was 'do not take any new risks for the present'." HORNE, Gerald. The Deepest South: The United States, Brazil, and the African Slave Trade. New York: New York University Press, 2007. p.30.

SILVA, Lígia Osório. Terras Devolutas e Latifúndio. Efeitos da Lei de 1850. Campinas: Ed. Unicamp 1996. escravo feliz. Antes bons negros da costa d'áfrica para cultivar nossos campos férteis do que todas as tetéias da rua do Ouvidor, do que vestidos de um conto e quinhentos mil réis para as nossas mulheres.

Para além dessa defesa extemporânea do tráfico negreiro, profundamente reveladora - como bem salientou Sérgio Buarque de Holanda ${ }^{20}$ - da visão de mundo escravista esposada oficialmente pela Maxwell, Wright \& Co, a crítica à expansão da base monetária pela desregulamentação bancária no Império do Brasil lembrava a experiência pretérita dos Estados Unidos durante a presidência de Andrew Jackson. Na leitura da firma,

\begin{abstract}
no ano de 1832 e alguns anos depois os governos da União dos Estados prestavam, não garantias de dividendos, porém, o seu crédito na forma de apólices, a várias empresas e essa legislação foi festejada por toda a parte com fogueiras e regozijo; todavia não decorreram mais que cinco anos que vários dos Estados se viram na humilhante posição de fazer bancarrota. Queira Deus que não nos aconteça o mesmo no Brasil.
\end{abstract}

A empresa havia acompanhado de perto os eventos financeiros da década de 1830, soberbamente examinados no ensaio de Edward Baptist. 0 historiador Gerald Horne cita uma carta de 29 de abril de 1837, na qual os gestores residentes nos Estados Unidos expressaram temores quanto ao contágio da crise de 1837 sobre os negócios da empresa no Rio de Janeiro. ${ }^{21} \mathrm{~A}$ historiografia atual não nos permite aquilatar quais riscos poderiam ameaçar, na praça carioca de 1837, uma firma como a Maxwell, Wright \& Co, haja vista que se sabe pouco a respeito do sistema comercial e financeiro do complexo exportador cafeeiro do Brasil nas décadas em que ele foi montado. Não há, para a primeira metade do século XIX, nada equivalente ao excelente trabalho de Joseph Sweigart, que cobre justamente o período de 1850 em diante. Seja como for, com base no conhecimento atualmente disponivel, pode-se afirmar que, a despeito do crescente atrelamento da economia cafeeira brasileira ao mercado consumidor norte-americano, as naturezas bastante distintas do mercado de capitais e do sistema de financiamento das atividades agro-exportadoras nos dois paises acabaram por colocar a cafeicultura ao abrigo das atividades especulativas que conferiram à economia escravista algodoeira do Sul seu caráter radicalmente moderno de boom and bust, ao mesmo tempo, contudo, em que encarecia o preço do dinheiro para os fazendeiros do Vale do Paraíba.

A raiz dessa diferença esteve na virtual ausência de um sistema de crédito hipotecário no Brasil, decorrente, como se sabe, do estatuto da terra por aqui. ${ }^{22} \mathrm{~A}$ terra no Brasil foi privatizada desde 0 início da colonização, mas seu estatuto jurídico incerto antes da segunda metade do século XIX não permitiu torná-la base para a contratação de empréstimos hipotecários. Toda a expansão da cafeicultura dependeu de um fluxo creditício que passava necessariamente pelos comissários do Rio de Janeiro, intermediários entre os fazendeiros de Serra Acima e as grandes casas exportadoras estrangeiras, como a Maxwell, Wright \& Co. Se por um lado esse sistema encareceu o custo do crédito para a cafeicultura brasileira, por outro ele não amarrou o fazendeiro - ao menos antes da década de 1870 - a uma cadeia de endividamento permanente com o comissário, haja vista a estratégia usual de negociar com vários comissários ao mesmo tempo, evitando atar-se a uma única casa comissária. ${ }^{23} \mathrm{E}$, podemos acrescentar, tampouco expôs o fazendeiro aos riscos de um mercado de capitais aberto, como o 
24

"Administração da Fazenda". Relatório do Presidente da Província do Rio de Janeiro, 1837, p.34-35. Disponivel em http://www.crl.edu/brazil/ provincial/rio_de_janeiro (acesso em 10 de junho de 2012)

25

É o que sugere a série relativa ao Vale do Paraiba preparada por MELLO, Pedro Carvalho de. A economia da escravidão nas fazendas de café: 1850-1888. Rio de Janeiro: Programa Nacional de Pesquisa Econômica, 1984, Vol.I, p.102. Para a tendência de preços dos escravos no mercado brasileiro, tendo por base a Província de Minas Gerais, ver BERGAD, Laird. Escravidão e História Econômica. Demografia de Minas Gerais, 1720-1888. (Trad.port.) Bauru, SP: Edusc, 2004 p.267. Sua série mostra um aumento considerável dos preços entre 1834-1850, mas bem menos agudo do que ocorreu entre 1829-1834 (sob o efeito da proibição legal do tráfico) e, em especial, após 1850 (em decorrência do fim definitivo do tráfico transatlântico).
Sobre a produtividade do solo e do trabalho, ver MARQUESE, Rafael; TOMICH, Dale. 0 Vale do Paraiba escravista e a formação do mercado mundial do café. In: GRINBERG, Keila; SALLES, Ricardo (org.). O Brasil Imperial. Volume II: 1831-1870. Rio de Janeiro: Civilização Brasileira, 2009, p.339-383. Sobre o câmbio, ver o trabalho esclarecedor de MOURA F., Heitor Pinto de. Câmbio de longo prazo do mil-réis: uma abordagem empírica referente às taxas contra a libra esterlina e o dólar (1795-1913). Cadernos de História, Belo Horizonte, v.11, n. 14, p.9-34, $1^{\circ}$ sem. 2009. era o Sul dos Estados Unidos. A crise financeira de 1837 serve de teste provisório para o que estou afirmando. No Relatório da Presidência do Rio de Janeiro relativo àquele ano, deu-se a notícia de um certo impacto da crise nos Estados Unidos na Província, como a suspensão de pagamentos por parte das firmas exportadoras e a diminuição temporária no volume de atividade dos negócios cafeeiros, mas sem quaisquer sinais de quebradeira dos fazendeiros do Vale do Paraiba. ${ }^{24}$

0 tráfico negreiro ilegal, ao garantir a estabilidade relativa do preço dos trabalhadores escravizados entre $1834-1850^{25}$, somado à agronomia da cafeicultura e às peculiaridades do funcionamento do mercado de crédito local, amorteceu os eventuais efeitos negativos da crise mundial de 1837. A assertiva adquire maior concretude se compararmos as flutuações dos preços do algodão e do café entre 1821-1860:

Preços médios anuais do algodão de fibra curta, Nova Orleans / Preços médios de importação do café para os Estados Unidos, New York (centavos de dólar por libra).

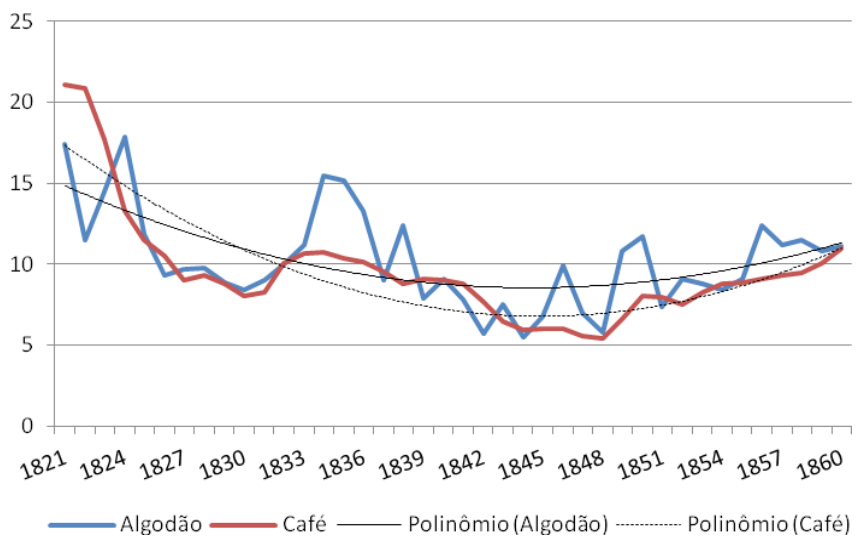

Fontes: Stuart Bruchey (comp. \& ed.). Cotton and the Growth of the American Economy: 1790-1860. Sources and Readings. New York: Harcourt, Brace \& World, Inc., 1976, Table P; CUNHA, Mauro Rodrigues da. Apêndice Estatístico. In: Marcelino Martins \& E. Johnston. 150 anos de Café. São Paulo: Marcellino Martins \& E. Johnston Exportadores Ltda., 1992, Tabela 1.8, p.333.

0 que de saída chama atenção é a congruência estreita entre as duas curvas, expressão da integração do mercado mundial de commodities sob o regime da Segunda Escravidão. Pode-se ver, também, a tendência de equilibrio entre as duas pontas da cadeia mercantil do café, isto é, entre a capacidade de importação dos Estados Unidos (mantida com os superávits gerados pela exportação de algodão para a Inglaterra) e a capacidade de exportação do Brasil. Há, entretanto, duas distinções importantes entre essas curvas. Primeiro: o algodão verificou oscilações muito mais fortes, 0 que se explica pelo fato de se tratar de uma cultura anual, portanto capaz de responder prontamente às ondas de expansão e retração da demanda conforme os movimentos especulativos do mercado, e cujo volume de produto era muitíssimo maior do que o café. Segundo: a tendência de queda mais acentuada dos preços do café entre 1821-1848, expressão do processo de massificação do mercado consumidor gestado pela sobreoferta brasileira, cujas perdas em termos de valor unitário foram mais do que contrabalançadas pelo colchão dado pelo baixo custo dos escravos, pela produtividade do solo e do trabalho no Vale do Paraiba e, não menos importante, pela tendência secular de desvalorização do mil-réis frente ao dólar. ${ }^{26}$ 
27

Ver, a respeito, DELFIM NETTO, Antonio. 0 problema do café no Brasil (1 ${ }^{\text {a ed: }}$ 1959). Campinas: Ed.FACAMP-Unesp, 2009; MELLO, Pedro Carvalho de. A economia da escravidão nas fazendas de café: 1850-1888. Rio de Janeiro: Programa Nacional de Pesquisa Econômica, 1984, v.l, p.12.

28

Aspecto bem salientado por GRAHAM, Richard. Economics or Culture?... Op. Cit., p.110.

29

Ver, a propósito, BERGAD, Laird W. The Comparative Histories of Slavery in Brazil, Cuba and the United States. Cambridge: Cambridge University Press, 2007. p.158-161.

30

SWEIGART, Joseph E. Coffee Factorage and the Emergence of a Brazilian Capital Market, 1850-1888. New York: Garland Publishing, 1987. p.112-117.

Recebido para publicação em fevereiro de 2013 Aprovado em março de 2013
As naturezas distintas dos ciclos agrícolas do algodão e do café são igualmente relevantes. Como foi possivel ler no ensaio de Edward Baptist, durante a crise de 1837, os senhores sulistas reagiram aos estímulos do BUS plantando mais algodão no ano seguinte, o que gerou, em 1839, um mergulho ainda mais fundo na crise. Os produtores algodoeiros, manejando uma planta anual, reagiam de imediato ao mercado, e para tanto o fluxo de caixa lhes era absolutamente vital. A estrutura da oferta do café seguia um ritmo bem diferente, em vista do caráter de bens de capital dos cafeeiros. ${ }^{27}$ Sendo "capitalizada", a cultura do café facultava aos produtores uma dependência menor em relação ao fluxo de caixa; com boas tulhas, poderiam armazenar café em coco de um ano para outro, na espera de ventos melhores. Aos planters sulistas era impossivel estocar seus enormes fardos de algodão, e por isso eram remetidos imediatamente aos portos exportadores (New Orleans, Mobile etc) após o beneficiamento.

Por fim, o algodão e o café estavam presos a cadeias mercantis da economia mundial com graus muito diferentes de desenvolvimento das instituições financeiras. ${ }^{28}$ Porém, se os cafeicultores brasileiros não tiveram facilidades equivalentes de crédito, isto os pôs ao abrigo das crises financeiras que afetaram periodicamente os produtores algodoeiros do Sul dos Estados Unidos. Até 1850, a estreita correlação entre os preços do algodão e os preços do café não encontrou equivalência nos preços dos escravos no Brasil e nos Estados Unidos. Tal convergência só ocorreu após aquela data. ${ }^{29}$ Eis uma implicação importante da continuidade do tráfico transatlântico negreiro sob a ilegalidade e da ausência de uma "financeirização" completa da cafeicultura brasileira: antes de 1850, as carteiras de crédito que os fazendeiros mantiveram abertas com os comissários, mais do que enredá-los em cadeias de endividamento, expressavam a relativa dependência dos próprios comissários em relação a eles. 0 que não significa que a cafeicultura escravista brasileira não guardou relações com o sistema financeiro mundial: afinal, firmas exportadoras como a Maxwell, Wright \& Co, diretamente conectadas aos fluxos de capitais internacionais, adquiriam café dos comissários adiantando-Ihes crédito que eventualmente era repassado aos fazendeiros, ou então vendiam aos traficantes os vasos que traziam da África a força de trabalho cativa necessária à expansão da cafeicultura. 0 ponto a enfatizar é que a inexistência de um crédito hipotecário consolidado por meio de instituições financeiras locais não representou obstáculo para o notável crescimento da produção das fazendas do Vale do Paraíba nas décadas de 1830-1840. Esse quadro começou a se alterar na década de 1850, com o fim definitivo do tráfico transatlântico de escravos. 0 código comercial aprovado naquele ano regulou a fundação de novos bancos, que absorveram parte dos capitais antes alocados no tráfico. As casas comissárias adotaram novas estratégias de gestão, que, se por um lado endureciam os termos de concessão do crédito aos fazendeiros, por outro Ihes ofereciam novos mecanismos para obtê-lo. ${ }^{30}$ Houve, então, certa congruência entre o que se passou a praticar no Sul dos Estados Unidos e o que se consolidou nas províncias cafeeiras do Brasil.

A compreensão integrada desses movimentos requer mais pesquisa, e deve incorporar necessariamente a cadeia mercantil do açúcar para que o desenho sobre a história financeira da Segunda Escravidão seja completo. As notas que apresentei tiveram o propósito apontar alguns caminhos para o café. Tanto em um caso como em outro, não há dúvidas de que o texto de Edward Baptist nos oferece um excelente modelo para tocarmos adiante tal tarefa. 